Pesq. Vet. Bras. 37(7):781-784, julho 2017

DOI: $10.1590 / \mathrm{S} 0100-736 \mathrm{X} 2017000700020$

\title{
Comparação entre os valores da amplitude de distribuição de diâmetro dos eritrócitos e do volume corpuscular médio com a citometria de eritrócitos em cães com leishmaniose ${ }^{1}$
}

\author{
Paulo H. Braz ${ }^{2 *}$, Marcel C. Sartoretto ${ }^{3}$, Adrian S. Souza ${ }^{4}$ e Mayara S. Siqueira ${ }^{3}$
}

\begin{abstract}
Braz P.H., Sartoretto M.C., Souza A.S. \& Siqueira M.S. 2017. [Comparison of amplitude values of the diameter distribution of erythrocyte volume and mean corpuscular cytometry with erythrocytes in dogs with leishmaniasis.] Comparação entre os valores da amplitude de distribuição de diâmetro dos eritrócitos e do volume corpuscular médio com a citometria de eritrócitos em cães com leishmaniose. Pesquisa Veterinária Brasileira 37(7):781-784. Centro Universitário da Grande Dourados, Dourados, MS 79824900, Brazil. E-mail: pauloh.braz@hotmail.com

Leishmaniasis is an endemic zoonosis that affects different animals species, among them the dogs. As an aid in the diagnosis and prognosis of the patient is routinely asked the CBC, which is characterized by anemia normocytic and normochromic type. The mean corpuscular volumes (MCV) and mean corpuscular hemoglobin concentration (MCHC) are the standards used for the classification of anemia, however, in recent years begun to use the amplitude diameter distribution of red blood cells (RDW) to distinguish anemias in regenerative and arregenerativas. This study aims to compare the RDW and MCV values with the erythrocyte cytometry in dogs with leishmaniasis. blood of 19 dogs of different breeds and ages were collected. The blood samples were processed in automatic equipment to obtain the MCV and RDW and later made blood smears for counting and measuring erythrocyte hundred cells from each slide. To evaluate the dispersion between the RBC values used the linear coefficient of Pearson. The RDW were more sensitive to anemia than VCM as compared with erythrocyte cytometry.
\end{abstract}

INDEX TERMS: Erythrocytes, cytometry, dogs, leishmaniasis, anemia, anisocytosis, haematocrit, RDW, VCM.

RESUMO.- A leishmaniose é uma zoonose de caráter endêmico que acomete diferentes espécies animal, dentre elas os cães. Como auxílio no diagnóstico e prognóstico do paciente é rotineiramente solicitado o hemograma, que é caracterizado por uma anemia do tipo normocítica e normocrômica. Os valores de volume corpuscular médio (VCM) e concentração de hemoglobina corpuscular médio (CHCM) são os padrões utilizados para a classificação da anemia, no entanto, nos últimos anos começou-se a utilizar a amplitude de distribuição de diâmetro dos eritrócitos (RDW) para

\footnotetext{
${ }^{1}$ Recebido em 28 de maio de 2016.

Aceito em 18 de novembro de 2016.

${ }^{2}$ Docente, Centro Universitário da Grande Dourados (UniGran), Rua Balbina de Matos 2121, Jardim Universitario, Bairro 900, Dourados, MS 79824010, Brasil. *Autor para correspondência: pauloh.braz@hotmail.com

${ }^{3}$ Discente em Medicina Veterinária, UniGran, Rua Balbina de Matos 2121, Jardim Universitario, Bairro 900, Dourados, MS 79824-010, Brasil.

${ }^{4}$ Discente em Farmácia na Universidade Católica Dom Bosco (UCDB), Av. Tamandaré 6000, Jardim Seminario, Campo Grande, MS 79117-900, Brasil.
}

diferenciar as anemias em regenerativas e arregenerativas. Este trabalho tem como objetivo comparar os valores de RDW e do VCM com a citometria eritrocitária em cães com leishmaniose. Foram colhidos sangue de 19 cães de diferentes raças e idades. As amostras sanguíneas foram processadas em equipamento automático para obtenção dos valores de VCM e RDW e posteriormente confeccionados esfregaços sanguíneos para contagem e medição de cem células eritrocitárias de cada lâmina. Para avaliar a dispersão entre os valores de hemácias utilizou-se o coeficiente linear de Pearson. Os valores de RDW mostraram-se mais sensíveis a anemia do que o VCM, quando comparados a citometria eritrocitária.

TERMOS DE INDEXAÇÃO: Eritrocitos, citometria, caninos, leishmaniose, anemia, anisocitose, hematócrito, RDW, VCM.

\section{INTRODUÇÃo}

A responsabilidade do médico veterinário frente às diversas doenças que acometem os animais fez com que hou- 
vesse a necessidade de resultados laboratoriais rápidos e confiáveis. Para isso, equipamentos automatizados para a realização do hemograma estão cada vez mais precisos e os resultados fidedignos, quando comparados aos exames realizados manualmente.

A classificação da anemia em microcítica, normocítica ou macrocítica acontece pelo valor correspondente ao volume corpuscular médio (VCM) da hemácia. Quando existem alterações no diâmetro eritrocitário, correspondentes aos macrócitos e micrócitos circulantes, denomina-se anisocitose eritrocitária. Quando isso ocorre, o valor do VCM pode estar alterado. (Weiser 1982, Harold 2010).

A amplitude de distribuição de diâmetro dos eritrócitos (RDW), tem como proposta oferecer uma resposta fidedigna da intensidade de anisocitose sem o auxílio da análise microscópica, no entanto, apenas nos últimos anos começou a ser difundida na medicina veterinária (Hodges \& Christopher 2011, Riond et al. 2011).

A leishmaniose em cães é uma doença que causa uma discreta anemia do tipo normocítica e normocrômica, conforme já descrito por alguns autores (Ikeda-Garcia et al. 2003, Mattos Jr et al. 2004, Braz et al. 2015), entretanto, não há estudos correlacionando os valores de RDW e VCM com a citometria eritrocitária em cães com leishmaniose visceral.

Os, parâmetros morfométricos celulares são recursos que podem ser usados para determinar grau de doenças hematológicas e neoplásicas. Esta técnica foi bastante empregada na medicina na década de 80, no entanto, não há dados morfométricos que sejam aplicados a eritrócitos de cães (Brahmi et al. 2001).

Neste contexto, tendo em vista a escassez de estudos avaliando a relação entre o RDW e VCM com a citometria, este trabalho tem como objetivo testar a hipótese de que RDW é um índice hematimétrico mais sensível na avaliação da anisocitose, considerando-se diferentes graus de anemia em cães com leishmaniose, naturalmente infectados e positivos pelo teste parasitológico.

\section{MATERIAL E MÉTODOS}

Neste estudo foram utilizados 19 cães de diversas raças e idades, provenientes do Centro de Controle de Zoonose de Dourados, MS. Os animais foram submetidos à punção aspirativa por agulha fina em linfonodo poplíteo para a pesquisa de formas amostigota de Leishmania spp. Os cães positivos ao teste foram submetidos à colheita de sangue venoso e as amostras acondicionadas em tubo contendo anticoagulante do tipo EDTA-K3 e encaminhadas ao Laboratório de Patologia Clínica do Hospital Veterinário do Centro Universitário da Grande Dourados (UniGran).

As amostras de sangue foram inicialmente processadas em leitor Automatizado Roche pocH-100iV Diff para a mensuração dos valores de RDW e VCM. Imediatamente após a leitura automatizada, iniciou-se a confecção de esfregaço sanguíneo para análise da citometria eritrocitária.

Para a mensuração do diâmetro eritrocitário, foram selecionados de cada lâmina 10 campos escolhidos ao acaso. Após selecionado o campo de contagem, foram escolhidas 5 hemácias com maior diâmetro aparente e 5 hemácias com diâmetro menor, correspondendo visualmente a maior variação de anisocitose. Sendo assim, para cada esfregaço sanguíneo foram medidos cem eritrócitos. As lâminas foram analisadas e fotomicrografadas com fotomicroscópio Axioskop-Zeiss. Ao microscópio de luz (Olympus BX-50) foram observados graus de anisocitose e alterações morfológicas eritrocitárias.

A anisocitose observada e medida foi distribuída pela Correlação Linear de Pearson. Quanto mais próximo o valor estiver de 1 ou -1, mais forte é a associação linear entre as duas variáveis. Os valores de RDW e VCM foram comparados com os resultados estatísticos.

\section{RESULTADOS E DISCUSSÃO}

Dentre os 19 animais avaliados, 12 eram anêmicos e 7 não possuíam anemia. Quando realizada a classificação morfológica do tipo de anemia, $75 \%(\mathrm{n}=9)$ era do tipo normocítica e normocrômica, enquanto $25 \%(\mathrm{n}=3)$ era do tipo microcítica e normocrômica. Devido ao acúmulo de deposição de imunocomplexos no eixo cardiorrenal, há destruição glomerular com perda da função endócrina renal, caracterizando a anemia como arregenerativa (Godoy et al. 2016, Braz et al. 2015). Os resultados dos valores de VCM e CHCM encontram-se no Quadro 1.

Com a utilização da citometria foi possível delinear o tamanho e a morfologia das hemácias (Figura 1) para posterior comparação com o RDW e o VCM (Figura 2). A Figura 3 apresenta a variação da média da distribuição linear pela Correlação Linear de Pearson.

Dentre os cães anêmicos, 33,3\% (n=4) apresentaram o RDW acima do valor de referência. Quando comparado à citometria eritrocitária foi possível notar que há uma correlação fraca positiva, demonstrando o alto grau de anisocitose das hemácias. Entretanto, em todos os casos, houve evidente anisocitose demonstrada pela citometria. Porém, quando comparada ao VCM, a classificação das hemácias foi do tipo normocítica.

0 aumento significativo do RDW apenas em 4 cães com anemia, sugere que as anemias discretas ou arregenera-

Quadro 1. Valores de amplitude de distribuição de diâmetro dos eritrócitos (RDW), Volume Globular (VG). Volume Corpuscular Médio (VCM) e Concentração de Hemoglobina Corpuscular Média (CHCM) de dos 19 cães, avaliados hematologicamente

\begin{tabular}{cccccc}
\hline Animal & RDW-CV \% & RDW-SD Fl & VG \% & VCM fl & CHCM g/dl \\
\hline 1 & 12,7 & 35.5 & 58.0 & 64.3 & 35.9 \\
2 & 14,8 & 37.1 & 38.1 & 59.1 & 33.3 \\
3 & 12.1 & 34.1 & 49.9 & 65.1 & 35.9 \\
4 & 21.5 & 51.3 & 11.1 & 70.7 & 34.2 \\
5 & 20.3 & 37.8 & 22.4 & 48.1 & 30.8 \\
6 & 16.0 & 39.3 & 31.7 & 58.8 & 32.5 \\
7 & 12.6 & 32.5 & 28.2 & 63.8 & 35.8 \\
8 & 19.5 & 43.9 & 21.7 & 61.0 & 34.1 \\
9 & 11.4 & 32.8 & 37.2 & 63.3 & 35.2 \\
10 & 13.7 & 37.5 & 34.7 & 63.4 & 33.4 \\
11 & 14.4 & 33.0 & 43.8 & 54.6 & 35.4 \\
12 & 10.4 & 31.6 & 41.0 & 63.4 & 37.1 \\
13 & 11.6 & 30.5 & 28.7 & 61.1 & 35.2 \\
14 & 12.9 & 36.4 & 38.7 & 66.8 & 34.4 \\
15 & 12.6 & 36.2 & 32.5 & 67.6 & 32.6 \\
16 & 13.5 & 30.4 & 19.0 & 58.1 & 32.6 \\
17 & 15.0 & 38.4 & 26.8 & 65.2 & 32.5 \\
18 & 19.6 & 43.1 & 20.3 & 60.6 & 33.0 \\
19 & 12.7 & 38.1 & 33.8 & 71.2 & 34.6
\end{tabular}




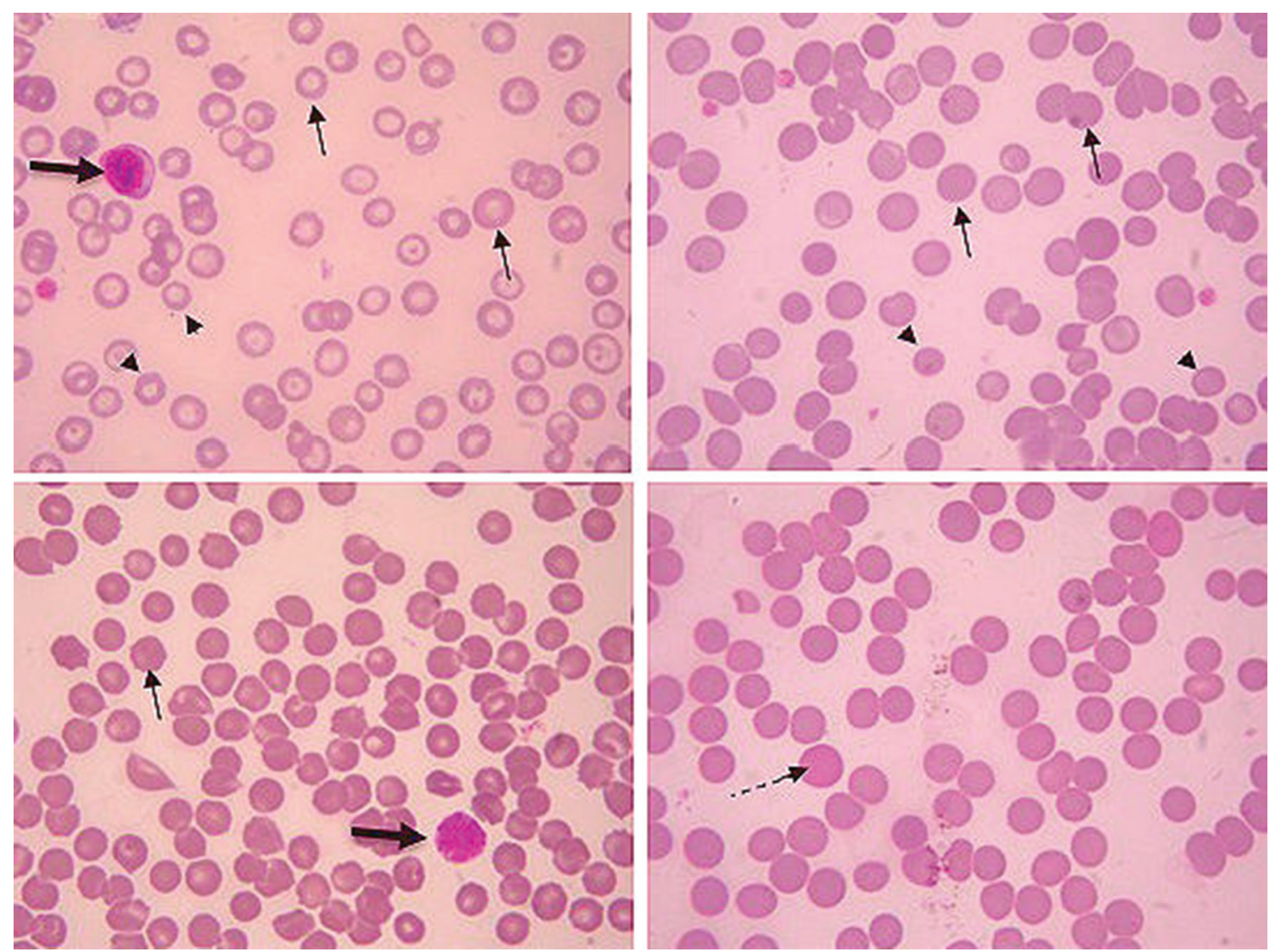

Fig.1. Hemácias de cães positivos para Leishmania sp. Observa-se marcante anisocitose representada por eritrócitos grandes (setas menores) e pequenos (cabeça da seta) e células em policromasia (setas pontilhadas). Há metarrubrícitos bem diferenciados (Seta maior e mais espessa) demonstrando regeneração medular.

tivas induzem pouca ou nenhuma resposta medular, haja visto que não ocorre alteração na variação das hemácias e nem do RDW (Balarin et al. 2001). Em animais com leishmaniose, a hipóxia talvez se torna insuficiente para promover aumento de eritropoietina devido as degenerações renais (Cowgill et al. 2003, Galvão et al. 2014).

Quando levado em conta os animais que não eram anêmicos foi possível observar que quanto maior o hematócrito, maior era a correlação linear. Nos animais em que o hematócrito estava acima de $45 \%$ a correlação de Pearson

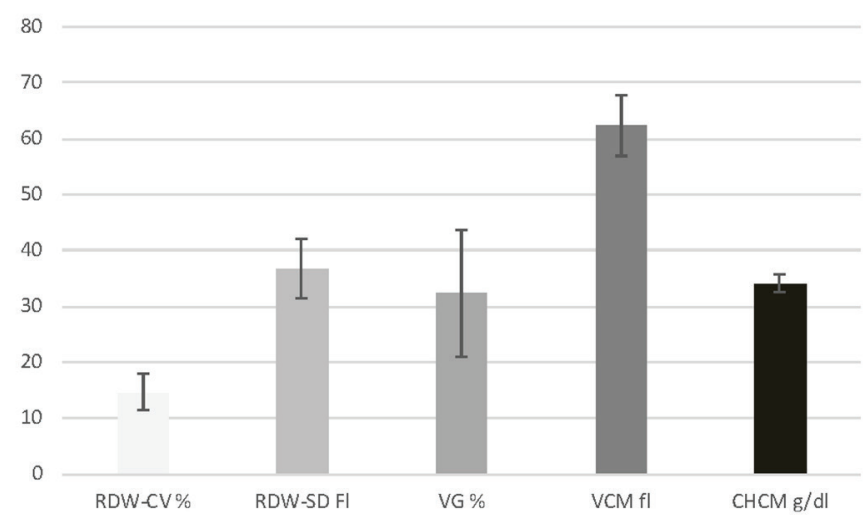

Fig.2. Distribuição da variação encontrada dos valores de RDW-CV, RDW-SD, VG, VCM e CHCM, dos 19 cães positivos para Leishmania sp.

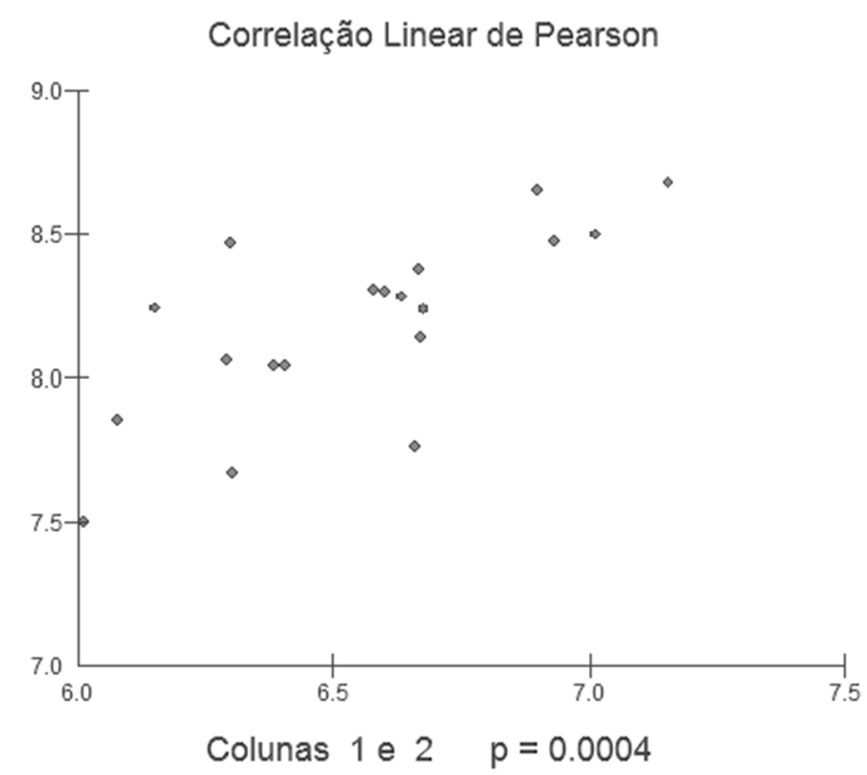

Fig.3. Distribuição da média do tamanho das hemácias de cães naturalmente infectados por Leishmania sp., utilizando a Correlação Linear de Pearson.

encontrava-se com $p>0,78$. Já, animais com hematócrito próximo ao limite interior de referência (37 - 40\%) apresentaram correlação de Pearson com 0,07 p<0,19.

Os animais com volume globular acima de $45 \%$ obtive- 
ram valores de RDW significativamente inferior ao grupo de animais anêmicos. Estes valores se devem ao fato destes animais não necessitarem de uma resposta medular para reposição celular. Tais dados corroboram com Flaiban \& Balarin (2004) que classificaram o valor de RDW de acordo com a porcentagem do hematócrito e encontraram valores de RDW menor em cães sem anemia. No entanto, para melhor credibilidade dos valores de RDW, não se deve desprezar valores altos em animais com valores de hematócrito dentro do intervalo de normalidade, sem verificar uma possível hemoconcentração devido à desidratação (Neiger et al. 2002).

A classificação morfológica das hemácias depende dos valores de VGM, entretanto, um grande volume celular deve estar alterado para resultar em um valor anormal (Weiser 1982). Animais com hematócrito dentro do valor de normalidade tiveram valores significativamente maiores que animais anêmicos.

\section{CONCLUSÕES}

A utilização do RDW verificado isoladamente não permite distinguir se a variação do diâmetro eritrocitário se deve ao encontro de macrócitos, micrócitos ou ambos. Por outro lado, a associação do RDW com a citometria e o valor do VCM permite maior sensibilidade ao exame.

Isoladamente o RDW demonstrou ser um teste mais sensível do que o VCM, quando comparado a citometria eritrocitária.

A leishmaniose visceral canina tem por característica uma anemia do tipo normocítica e normocrômica e o RDW demonstrou ser um bom marcador nos casos em que ainda não há comprometimento renal com consequente regeneração celular.

\section{REFEFÊNCIAS}

Balarin M.R.S., Fonteque J.H., Souza C., Saito M.E., Kohayagawa A. \& Lopes R.S. 2001. Valores da amplitude de distribuição do tamanho dos eritrócitos (RDW) em eqüinos da raça Puro Sangue Inglês (PSI) de ambos os sexos de 12 a 24 meses de idade. Semina, Ciênc. Agrárias 22:135-137.
Brahmi U., Rajwanshi A., Joshi K., Dey P., Vohra H., Ganguly N.K. \& Gupta S.K. 2001. Automated nuclear image morphometry on fine needle aspiration smears of malignant round cell tumors. Anal. Quant. Cytol. Histol. 23(4):287-290.

Braz P.H., Sartoretto M.C., Souza A.S. \& Melo F.M.G. 2015. Perfil hematológico de cães naturalmente infectados por Leishmania spp. Acta Vet. Bras. 9:87-90.

Cowgill E.S., Neel J.A. \& Grindem C.B. 2003. Clinical application of reticulocyte counts in dogs and cats. Vet. Clin. Small Anim. Pract. 33:12231244.

Flaiban K.K.M.C. \& Balarin M.R.S. 2004. Estudo comparativo entre a amplitude de variação dos eritrócitos (RDW - Red Blood Cell Distribution Width) e o Volume Globular (VG), Volume Globular Médio (VGM) e a presença de anisocitose em extensão sangüínea em cães. Semina, Ciênc. Agrárias 25:125-130.

Galvão A.L.B., Palazzo E.L., Pinto M.L. \& Vieira M.C. 2014. Reactive oxygen species and chronic kidney disease: review. Nucl. Anim. 6:69-80.

Godoy K.C.S., Braz P.H., Assis A.R., Antunes T.R., Gomes D.C. \& Souza A.I. 2016. Avaliação dos indicadores de lesão miocárdica em cães com leishmaniose visceral. Arq. Bras. Med. Vet. Zootec. 68:313-320.

Harold T. 2010. Laboratory and clinical diagnosis of anemia, p.152-161. In: Schalm O.W., Weiss D.J. \& Wandrop K.J. (Eds), Schalm's Veterinary Hematology. 6th ed. Blackwell Publishing, Ames, Iowa.

Hodges J. \& Christopher M.M. 2011. Diagnostic accuracy of using erythrocyte indices and polychromasia to identify regenerative anemia in dogs. J. Am. Vet. Med. Assoc. 238:1352-1458.

Ikeda-Garcia F.A., Ciarlini P.C., Feitosa M.M., Gonçalves M.E., Luvizotto M.C.R. \& Lima V.M.F. 2003. Perfil hematológico de cães naturalmente infectados por Leishmania chagasi no município de Araçatuba, São Paulo: estudo retrospectivo de 191 casos. Clín. Vet. 47:42-47.

Mattos Jr D.G., Pinheiro J.M., Menezes R.C. \& Costa D.A. 2004. Aspectos clínicos e de laboratório de cães soropositivos para leishmaniose. Arq. Bras. Med. Vet. Zootec. 56:119-122.

Neiger R., Hadley J. \& Pfeiffer D.U. 2002. Differentiation of dogs with regenerative and non-regenerative anaemia on the basis of their red cell distribution width and mean corpuscular volume. Vet. Rec. 150:431434.

Riond B., Weissembacher S., Hofmann-Lehmann R. \& Lutz H. 2011. Performance evalution of the Symex pocH-100Iv Diff hematology analyzer for analysis of canine, feline, equine and bovine blood. Vet. Clin. Pathol. 40:484-395.

Weiser M.G. 1982. Erythrocyte volume distribution analysis in healthy dogs, cats, horses, and dairy cows. Am. J. Vet. Res. 43:163-166. 